\title{
PRESENTACIÓN DEL DOSSIER
}

\section{EDUCACIÓN MEDIADA POR TECNOLOGÍA: APRENDIZAJE, INNOVACIÓN Y PROSPECTIVA}

La educación en la posmodernidad, con la velocidad abrumadora de avances tecnológicos y acontecimientos sociales, se configura como un factor social trascendente y protagonista en una época de la historia de la humanidad en la cual se lucha por conseguir cambios fundamentales en los procesos evolutivos de la sociedad a partir de comprender y explicar una realidad con diferentes procesos complejos, que hasta hace poco, sólo el científico estaba a cargo de investigar para entender su lógica o racionalidad.

Los educadores hemos tenido la necesidad de buscar una nueva forma de interacción para lograr que el aprendizaje aproveche el vasto poder de las computadoras, el video, las tecnologías de la información y comunicación (TIC), la telemática y, que todo ello, permita mejorar el acto educativo.

En la actualidad la virtualización educativa no sólo hace referencia a una realidad, sino que se convierte en una necesidad y alternativa para el desarrollo social y económico de las naciones, en donde la formación y/o educación a distancia, on line, digital ó virtual, permite a estudiantes, profesores, facilitadores y administradores, tener un lugar de encuentro educativo en donde se fomente la autonomía del alumno a través de la búsqueda independiente del conocimiento, de manera paralela al desarrollo de sus habilidades para el trabajo colaborativo en espacios virtuales. ${ }^{1}$

La dinámica de evolución de la informática, las telecomunicaciones, las redes electrónicas y las tecnologías representan un núcleo de conocimiento para el debate de académicos e investigadores en Iberoamérica y el resto del mundo, lo anterior en virtud de su impacto en el ámbito educativo formal y no formal, en la generación de nuevas estrategias para la enseñanza-aprendizaje, la transformación de los modelos educativos, las contribuciones de las tecnologías emergentes en el proceso educativo, entre múltiples posibilidades susceptibles de análisis.

\footnotetext{
${ }^{1}$ Edel, R. (2007). La virtualización de los procesos educativos: más allá de las TIC. reflexiones de profesionales de la educación. metas educativa 2021. la educación que queremos para la educación de los bicentenarios. organización de estados iberoamericanos.
} 
Como punto de partida para su discusión podemos plantear que la tecnología tiene diversos retos que cumplir en la Educación, sin embargo, sus alcances no serán posibles sin comprender que la fórmula no se localiza en el cambio sino en la evolución de las formas de concebir, planear, implementar y evaluar las acciones educativas en el contexto social.

No sólo será suficiente contar con recursos tecnológicos sofisticados o modernos, tal es la experiencia del empleo de las plataformas tecnológicas en la educación en todos los niveles, de los alcances de la educación a distancia implementada por diferentes instituciones de Educación superior públicas y privadas en Iberoamérica, o la subutilización del software, hardware y recursos digitales en los centros educativos, por el contrario, se requiere crear estrategias, métodos o modelos que fundamenten el significado y la forma de enfrentar a la educación innovadora.

En la sociedad del conocimiento, se requiere formar usuarios y consumidores de tecnología; el hecho de que una institución educativa cuente con un centro de cómputo no significa que este se utilice o, al menos, que se utilice con tanta frecuencia como para considerar su uso rentable, parecería que la educación en Iberoamérica todavía no ha respondido con las expectativas generadas.

Ante la necesidad de formar personas capaces de utilizar la tecnología, las políticas, planes, autoridades e instituciones escolares sólo han respondido con alfabetización informática, condición análoga con la tarea de los docentes respecto a la tecnología, la cual no sólo se refiere a conocer las rutinas de su uso o aplicación, en contraste, su incorporación al proceso de enseñanza-aprendizaje-evaluación exige contemplar de manera distinta dicho proceso y dimensionar en qué medida afectará a todos los elementos que lo componen.

Cabe destacar, la preocupación por escuchar el discurso académico que la investigación sobre las TIC, como suele referírsele, deberá ser el propósito de la investigación y discusión educativa, sin embargo, deberá reconocerse que el estudio de las TIC representa sólo una línea de investigación o foco de interés sobre los entornos virtuales de aprendizaje (EVA), y que abrir el zoom en la prospectiva sobre el área de conocimiento en cuestión, nos conduciría a enriquecer la discusión sobre la virtualización en el proceso educativo, lo cual demanda profundizar en la naturaleza de los entornos emergentes de aprendizaje y su impacto en los procesos educativos, y por tanto, reconocerle como un objeto de estudio y discusión relevante en Iberoamérica. 
El presente número temático Educación mediada por Tecnología: Aprendizaje, Innovación y Prospectiva, en congruencia con la citada investigación y discusión educativa, integra 25 artículos que dan cuenta del proceso de enseñanza-aprendizaje en diferentes niveles de formación académica y en distintos contextos socioculturales de Iberoamérica, los cuales contribuyen con el Estado del $\mathrm{Arte}^{2}$ de los entornos virtuales de aprendizaje (EVA), y de manera particular, con el acervo de ocho campos del conocimiento asociados con;

1) Políticas para la instrumentación y equipamiento de las TIC en espacios educativos. Perspectivas sobre la calidad, evaluación y acreditación de la educación mediada por las TIC, implementación y desarrollo de tecnología educativa, telemática, software educativo, simuladores y laboratorios virtuales, el costo-beneficio del empleo de recursos digitales en la educación y la evaluación de planes y programas gubernamentales para la incorporación de TIC en el acto educativo.

2) Análisis sobre el empleo de las TIC en el proceso educativo. El aporte de los medios electrónicos y digitales (e-mail, chat, foro, videoenlace, videoconferencia, sonido e imagen digital, entre otros), en las prácticas educativas de una sociedad en red y mediada por tecnología. La innovación educativa en los entornos diferenciados y emergentes de aprendizaje, el aprendizaje móvil (smartphones y tablets), el homeschooling y el campo de conocimiento de la legislación y/o legalidad asociado con los entornos virtuales de aprendizaje.

3) La contribución de los espacios y recursos virtuales de aprendizaje. El impacto de las plataformas tecnológicas en la educación, la web X.0 (blogs, wikis, podcasts, e-books, páginas web, etc.), las aulas virtuales de escuelas, universidades y empresas, así como la influencia de las redes científicas y redes sociales en la Educación, el alcance didáctico de los objetos de aprendizaje, la realidad aumentada y las herramientas digitales de simulación.

${ }^{2}$ Edel, R. y Navarro, Y. (2015). Entornos virtuales de aprendizaje 2002-2011. Colección Estados del Conocimiento. Editado por ANUIES-COMIE. ISBN ANUIES 978-607-451-107-9, ISBN COMIE 978607-792-322-0. 
4) Análisis sobre la influencia del empleo de internet en los procesos educativos. Fundamentación teórica y empírica sobre el empleo didáctico de internet, el impacto de la brecha digital, la gestión y regulación de la educación a distancia, así como la investigación sobre el empleo de las TIC y los EVA para la inclusión social y el apoyo a grupos vulnerables.

5) Niveles, modelos y modalidades de educación mediados con tecnología. Explicaciones sistemáticas acerca de las modalidades educativas de la semipresencialidad, aprendizaje electrónico, mixto y móvil (e-b-m-net-learning), la educación abierta, la educación a lo largo de la vida, la dinámica de las universidades virtuales y abiertas, así como de sus constructos asociados con la equidad, pertinencia, calidad, cobertura, inclusión y contribución social.

6) El fenómeno de la virtualización educativa. La transferencia de la presencialidad a la virtualidad y el conectivismo en y para el aprendizaje. La influencia en los procesos cognitivos y su posible contribución en y para la transformación educativa.

7) El movimiento educativo abierto. Descripción. Conocimiento formal acerca de los recursos educativos abiertos, objetos de aprendizaje, repositorios, laboratorios remotos y virtuales, de la cultura del open-access y de los massive open on-line courses (MOOC), así como los derechos de autor, licenciamientos y sustentabilidad del recurso abierto.

8) Ciudadanía y competencias digitales. Aproximación formal a las competencias digitales (e-skills), al saber respecto de la contribución de las TIC en la formación inicial docente, la ciudadanía digital, la alfabetización y brecha digital y el manejo de la información-medios y el comportamiento social en internet (Facebook, Twitter, LinkedIn, Whatsapp, Instagram, Flickr, entre múltiples).

Sirvan las últimas líneas de la Presentación del Dossier para externar un sincero agradecimiento al colectivo de autores que permitieron concretar la presente obra, compartir sus experiencias, reflexiones y discusiones, demuestra su gran valor 
académico y profesional, el cual seguramente permitirá abonar en forma innovadora el campo de conocimiento sobre el Aprendizaje mediado por Tecnología.

Finalmente, hacer extensiva la gratitud a la Revista Iberoamericana de Estudios en Educación, por su invaluable espacio editorial y la difusión de este número temático.

Dr. Rubén Edel-Navarro

Coordinador del Dossier

Universidad Veracruzana

México 